\title{
A Small pH Sensor Catheter of the Endoscope for Acidity Test of Gullet and Stomach
}

\author{
Ji-Hyoung Roh', ${ }^{1,3}$ Kyu-Sik Shin ${ }^{1}$, Nam-Kyu Cho ${ }^{1}$, Don-Haeng Lee ${ }^{2}$, \\ Byung-Moo Moon ${ }^{3, *}$ and Dae-Sung Lee ${ }^{1, * *}$

\begin{abstract}
${ }^{1}$ Nano Sensor Research Center of Korea Electronics Technology Institute, \#68 Yatap-dong, Bundang-gu, Seongnam-si, Gyeonggi-do 463-816, Korea

${ }^{2}$ Digestive Disease Center of Inha University Hospital, 7-206 3-Ga, Sinheung-dong, Jung-gu, Incheon 400-711, Korea

${ }^{3}$ Department of Electrical Engineering, Korea University, 5-1 Anam-dong, Sungbuk-gu, Seoul 136-701, Korea
\end{abstract}

(Received August 1, 2008; accepted November 19, 2008)

Key words: gastroesophageal reflux disease (GERD), pH, ISFET, endoscope

The detection of $\mathrm{pH}$ in the gullet and stomach is highly significant for the diagnosis of gastroesophageal reflux disease (GERD), particularly with the use of a $\mathrm{pH}$ sensor in vivo. Most conventional $\mathrm{pH}$ sensors are used singly and could not be inserted in the endoscope's working channel. Because the ion sensitivity field-effect transistor (ISFET) chip has become very small, we have made the $\mathrm{pH}$ sensor smaller than a conventional glass $\mathrm{pH}$ sensor, and have used it. In this paper, we introduce a small in vivo $\mathrm{pH}$ sensor catheter of $2.7 \mathrm{~mm}$ diameter and $8 \mathrm{~mm}$ length, which can be put in the endoscopy's working channel of $3 \mathrm{~mm}$ diameter. The catheter was evaluated in buffer solution $(\mathrm{pH}$ $2-12$ ) and its sensitivity was $43 \mathrm{mV} / \mathrm{pH}$. It was confirmed that the catheter properly functioned during an animal experiment.

\section{Introduction}

With the advance of semiconductor sensor technology, DNA chips, lap-on-a-chip sensors, protein sensors and other similar devices have been used in medical diagnosis. There are few sensors that can probe the gastrointestinal (GI) tract. However, such sensors have limits in diagnosing stomach disorder. Physicians of digestive diseases have raised the need for a $\mathrm{pH}$ sensor catheter for the diagnosis of ulcers, tissue inflammation, hypo- or hyper- chlorhydria, achlorhydria, and esophageal acid exposure. Some wireless $\mathrm{pH}$ sensors have been developed recently, and physicians want to use a $\mathrm{pH}$ catheter during an endoscope test. ${ }^{(1-3)}$

The $\mathrm{pH}$ of the gullet and stomach is significant and useful for the diagnosis of GERD, particularly for functional diseases of GERD. Most conventional $\mathrm{pH}$ sensors are too large to put into an endoscope's working channel. Because an ion-sensitive field effect

Corresponding authors: e-mail: *byungmoo@korea.ac.kr, ${ }^{* *}$ leeds@keti.re.kr 
transistor (ISFET) $\mathrm{pH}$ sensor is smaller than a normal glass electrode $\mathrm{pH}$ sensor, it can be inserted and used as a $\mathrm{pH}$ sensor catheter in an endoscope working channel. However, it is difficult to make the reference electrode smaller and to maintain the performance as good as that of the large conventional one.

In this paper, we discuss the fabrication of an ISFET $\mathrm{pH}$ sensor catheter for insertion into an endoscope working channel and investigated the digestive organ.

\section{Structure and Fabrication}

\subsection{Structure of the ISFET pH sensor catheter}

An ISFET is a potentiometric $\mathrm{pH}$ sensor that is easily adapted to a wide range of chemical, biochemical, and biomedical measurements. Because an ISFET $\mathrm{pH}$ sensor is smaller than a conventional glass electrode $\mathrm{pH}$ sensor, it can be used to determine $\mathrm{pH}$ in the endoscope working channel. Figure 1 shows a schematic of the use of our ISFET $\mathrm{pH}$ sensor catheter. ${ }^{(4,5)}$

We designed, implemented, and evaluated a small ISFET $\mathrm{pH}$ sensor for insertion into an endoscope working channel. The $\mathrm{pH}$ sensor catheter is composed of an ISFET on a printed circuit board (PCB), a reference electrode, and electrical wires. The PCB width was limited to within $2.5 \mathrm{~mm}$ because the diameter of the endoscope working channel was $3 \mathrm{~mm}$. The reference electrode was fabricated using $\mathrm{Ag} / \mathrm{AgCl}$ wire $(0.5 \mathrm{~mm}$ diameter), $\mathrm{KCl}$ gel, and ion-exchangeable glass. The $\mathrm{pH}$ sensor catheter had a cap. It was made of polyetherimide (PEI), and was $2.7 \mathrm{~mm}$ in diameter and $8 \mathrm{~mm}$ in length.

The $\mathrm{pH}$ of an aqueous solution indicates the molar concentration of hydrogen ions. As with the schematics of other semiconductor ion sensors, the ISFET schematic is similar to that of a metal insulator semiconductor field-effect transistor (MISFET). The gate part of a MISFET is replaced with a reference electrode and becomes an ISFET

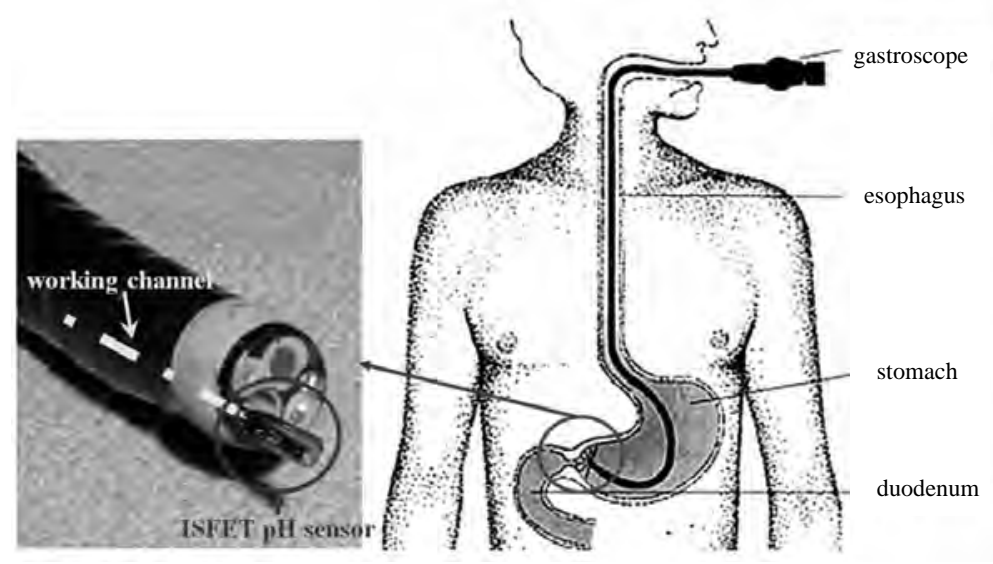

Fig. 1. Overall view of an ISFET $\mathrm{pH}$ sensor catheter in the endoscope. 
sensor with solution and ion sensitivity membranes. The reference electrode keeps the potential in the solution. Hydrogen ions in the solution react with silicon nitride on the sensing membrane, and an electrochemical potential difference is generated between the reference electrode and the sensing membrane. The potential difference is a function of ion concentration; it changes the channel conductivity between the source and drain of ISFET. Thus, the drain current was altered linearly to the $\mathrm{pH}$. Figure 2 shows a schematic of an ISFET.(4)

\subsection{Fabrication}

The size of the $\mathrm{pH}$ sensor was determined using the reference electrode because the small size of the ISFET is dependent on the size of the reference electrode. The miniaturization of the reference electrode is required to make the $\mathrm{pH}$ sensor acceptably small. Over the years, many research studies of quasi-metal electrodes and novel metals such as Au and Pt have been conducted. These studies showed that the $\mathrm{pH}$ sensor cannot be realized owing to the instability of the metal surface potential and extreme drift. Therefore, we developed a $\mathrm{pH}$ sensor catheter that has a very small reference tube, that is, a $\mathrm{Ag} / \mathrm{AgCl}$ electrode. To miniaturize the reference electrode, the quantity of $\mathrm{KCl}$, the reaction length of $\mathrm{Ag} / \mathrm{AgCl}$, and the aperture size of the ion exchange membrane were optimized through a number of experiments. Figure 3 shows a schematic of the ISFET

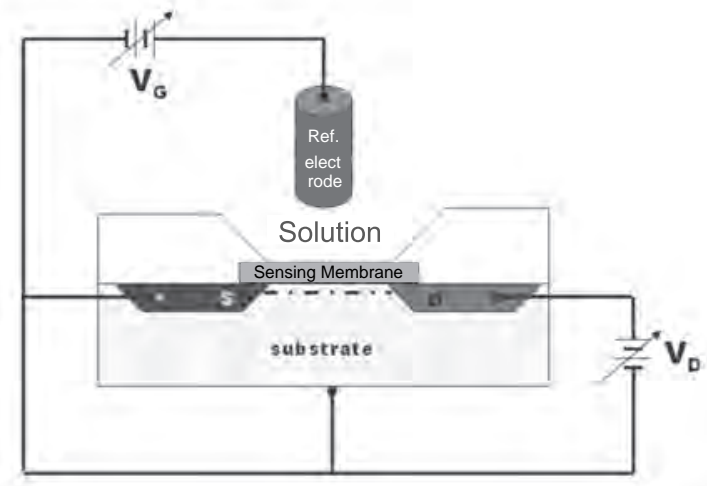

Fig. 2. Schematic of an ISFET.

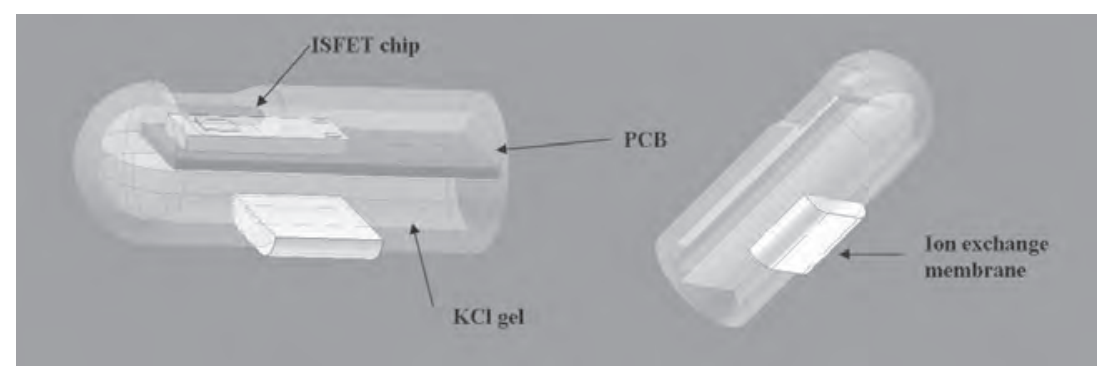

Fig. 3. Schematic of the ISFET pH sensor catheter. 
$\mathrm{pH}$ sensor head. The cap is divided into two parts. The ISFET chip is on the upper side and the reference $\mathrm{Ag} / \mathrm{AgCl}$ electrode kept in $\mathrm{KCl}$ gel is on the lower side.

The $\mathrm{pH}$ sensor catheter was packaged with silicon epoxy to protect it against strong acids and alkalis and to eliminate the leakage current of the ISFET. Silicon epoxy is thermostable, inactive, nonadhesive, insulated, and resistant to acids and alkalis.

The $\mathrm{pH}$ sensor catheter of $2.7 \mathrm{~mm}$ diameter and $8 \mathrm{~mm}$ length was fabricated for appropriate use in an endoscope's working channel of $3 \mathrm{~mm}$ diameter, as shown in Fig. 4. The reading circuit was a reference feedback circuit. This circuit keeps the drain current of the ISFET stable, and the voltage of the reference electrode increases with increasing $\mathrm{pH} .{ }^{(5-9)}$

\section{Results and Discussion}

\subsection{Sensitivity}

The most important property of the $\mathrm{pH}$ sensor catheter is reliability. Therefore, we carried out an experiment to compare our proposed electrode with a large reference electrode to confirm whether a small electrode will operate well. The large reference electrode was $4.5 \mathrm{~mm}$ in diameter and $7 \mathrm{~cm}$ in length, and the small one was $2.7 \mathrm{~mm}$ in diameter and $8 \mathrm{~mm}$ in length. We measured the $I_{\mathrm{d}}-V_{\mathrm{d}}$ and $I_{\mathrm{d}}-V_{\mathrm{g}}$ curve characteristics of the $\mathrm{pH}$ sensor with the large reference electrode using a semiconductor analyzer. Figure 5 shows the $I_{\mathrm{d}}-V_{\mathrm{d}}$ and $I_{\mathrm{d}}-V_{\mathrm{g}}$ curves of the $\mathrm{pH}$ sensor using the large reference electrode. The current difference at each $\mathrm{pH}$ increased linearly.

The $\mathrm{pH}$ sensor with the small reference electrode was also examined. Figure 6 shows that the $I_{\mathrm{d}}-V_{\mathrm{d}}$ and $I_{\mathrm{d}}-V_{\mathrm{g}}$ curves of the $\mathrm{pH}$ sensor using the small reference electrode are similar to those shown in Fig. 5. We confirmed that both electrodes have linearity in standard buffer $\mathrm{pH}$ solutions, as shown in Figs. 7 and 8. As the size of either electrode was reduced, the $I_{\mathrm{d}}$ current decreased from $149 \mu \mathrm{A}$ to approximately $49 \mu \mathrm{A}$. Thus, the sensitivity was decreased slightly but the output level increases orderly similarly to $\mathrm{pH}$.

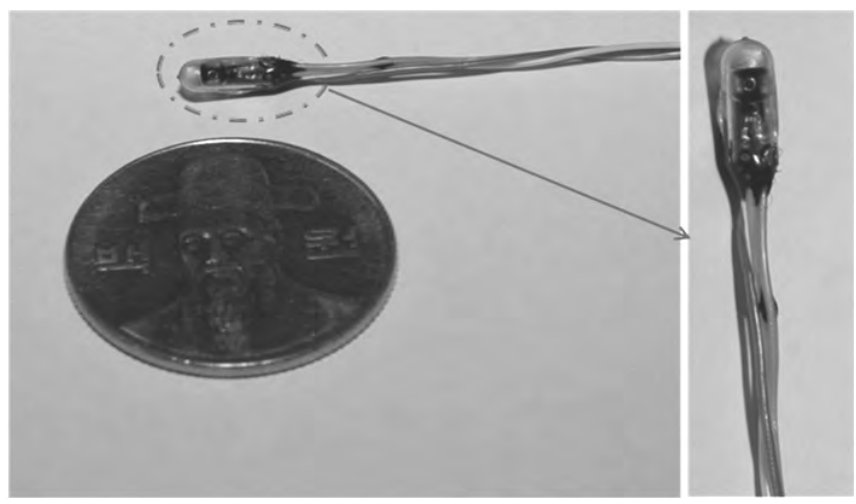

Fig. 4. Fabricated ISFET pH sensor catheter. 

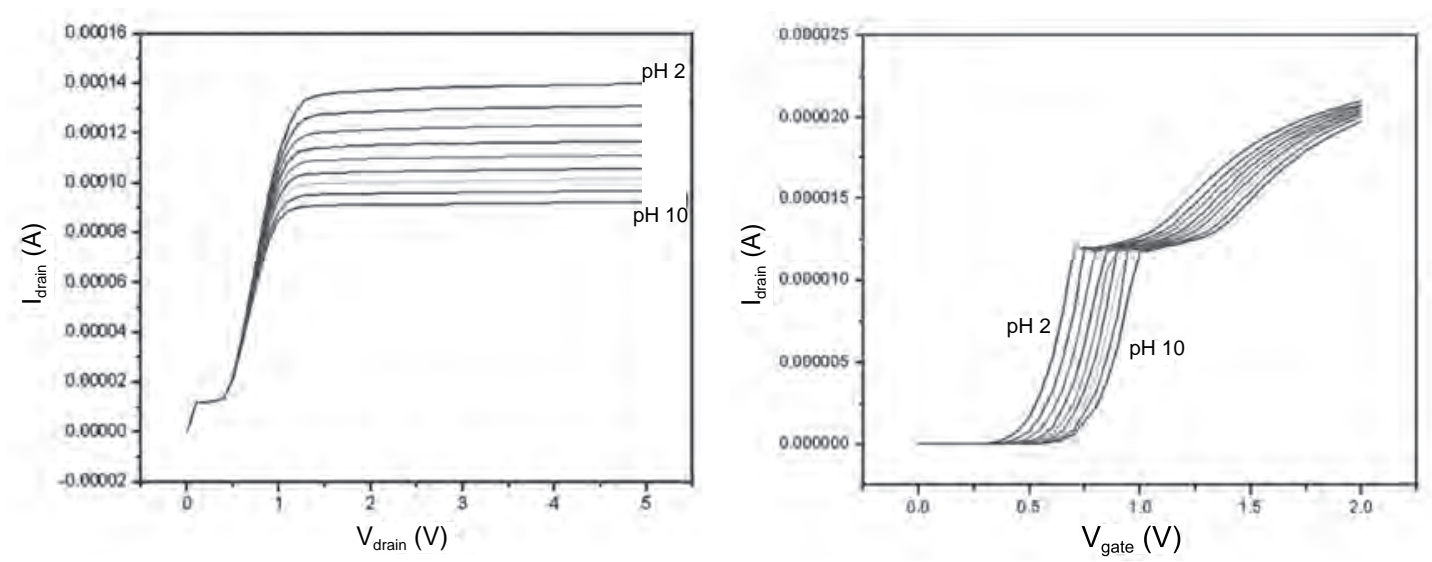

Fig. 5. $I_{\mathrm{d}}-V_{\mathrm{d}}$ and $I_{\mathrm{d}}-V_{\mathrm{g}}$ characteristics of large reference electrode.
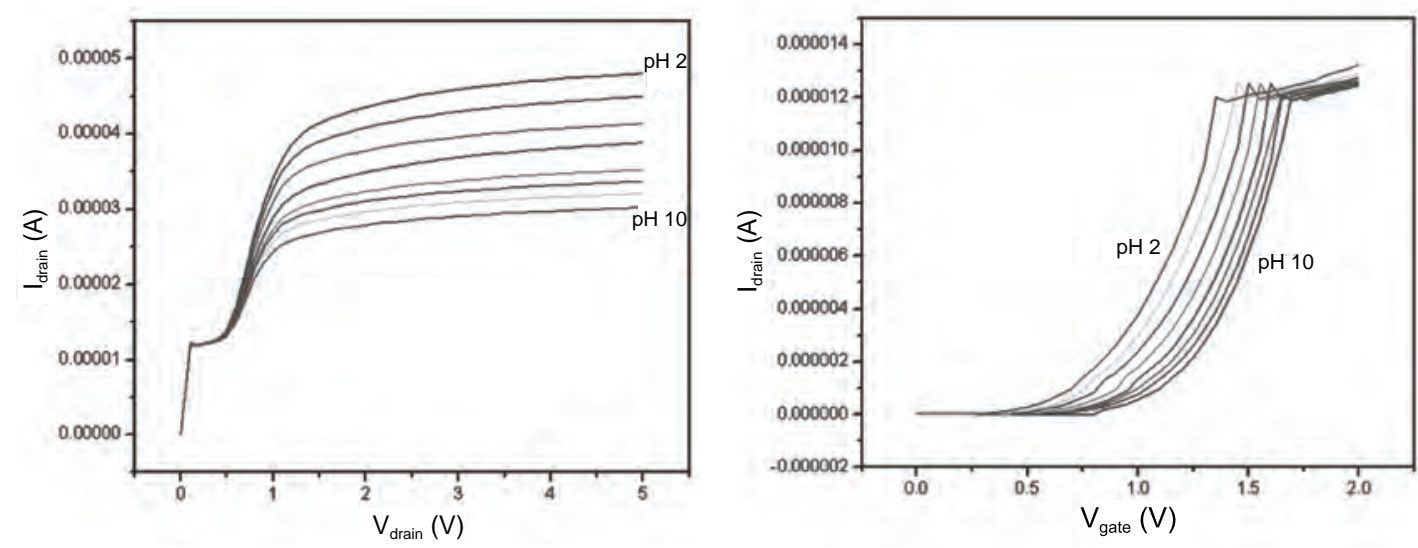

Fig. 6. $I_{\mathrm{d}}-V_{\mathrm{d}}$ and $I_{\mathrm{d}}-V_{\mathrm{g}}$ characteristics of small reference electrode. 

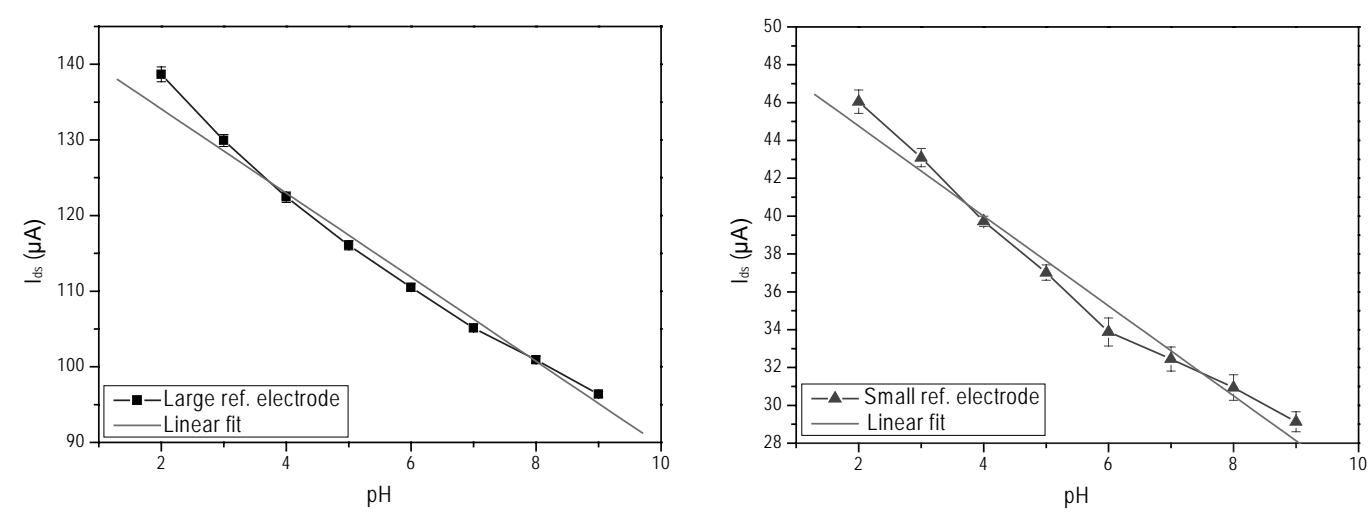

Fig. 7 (left). Sensitivity of large reference electrode.

Fig. 8 (right). Sensitivity of small reference electrode.

This work showed that it is possible to use the small reference electrode with an ISFET $\mathrm{pH}$ sensor.

The sensitivity of the $\mathrm{pH}$ sensor catheter was measured from $\mathrm{pHs} 2$ to 9 with the reference feedback circuit. It was dipped in each $\mathrm{pH}$ buffer solution for $1 \mathrm{~min}$. The sensitivity was $43 \mathrm{mV} / \mathrm{pH}$ from pHs 2 to 9 . The test was repeated four times, in both increasing and decreasing orders. The $\mathrm{pH}$ of the stomach and gullet is between 2 and 7 , and this sensor can be useful for the human body. Figure 9 shows the sensitivity of the $\mathrm{pH}$ sensor catheter.

\subsection{Long-term stability test}

The long-term stability test is essentially to confirm the reliability of the sensor. The catheter will be used in the stomach and gullet within 2 or $3 \mathrm{~h}$ at most. The $\mathrm{pH}$ sensor catheter was soaked in $\mathrm{pH} 2$ or 7 solution for $72 \mathrm{~h}$. The solution at $37^{\circ} \mathrm{C}$ was stirred with a magnetic bar. Figure 10 shows the long-term stability test results of the $\mathrm{pH}$ sensor catheter.

\subsection{In vivo animal test}

An in vivo test on the fabricated $\mathrm{pH}$ sensor catheter was carried out in a pig. The test was conducted with an endoscope, so we could determine where the catheter was. The $\mathrm{pH}$ sensor catheter worked well in the gullet and stomach of the pig. When the catheter reached the stomach, the $\mathrm{pH}$ dropped rapidly. Figure 11 shows that the catheter could determine the $\mathrm{pH}$ of a pig's alimentary canal. 


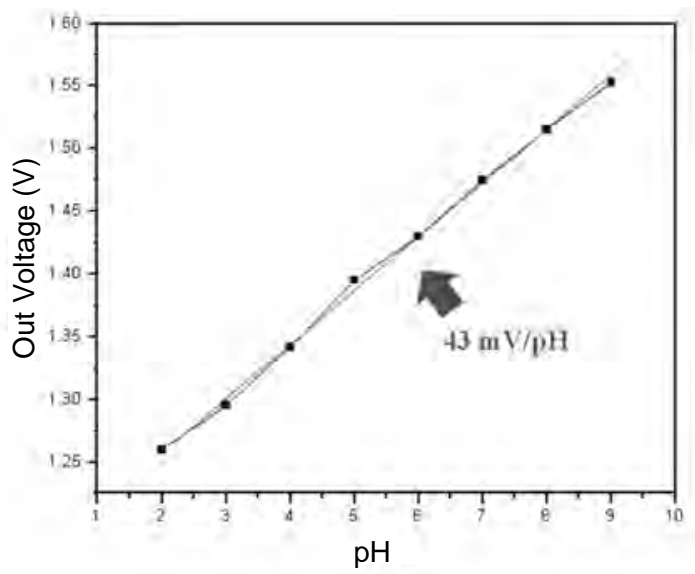

Fig. 9. Sensitivity of small $\mathrm{pH}$ sensor catheter of endoscope.

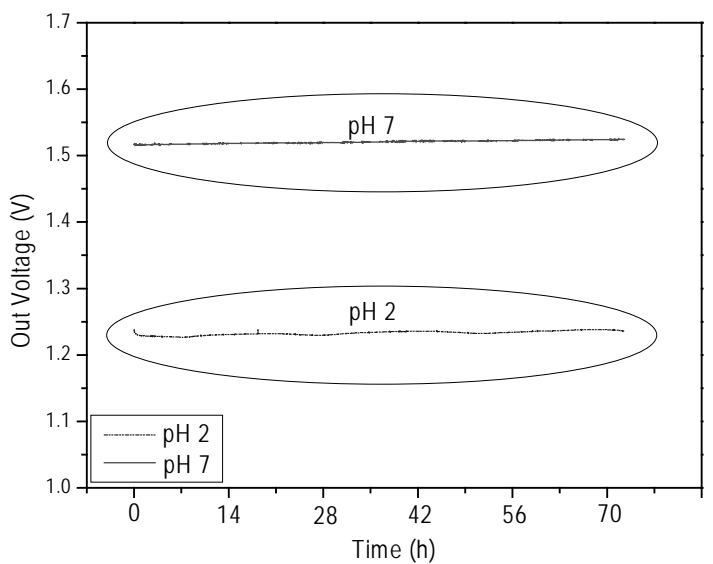

Fig. 10. Long-term stabilities at $\mathrm{pHs} 2$ and 7.

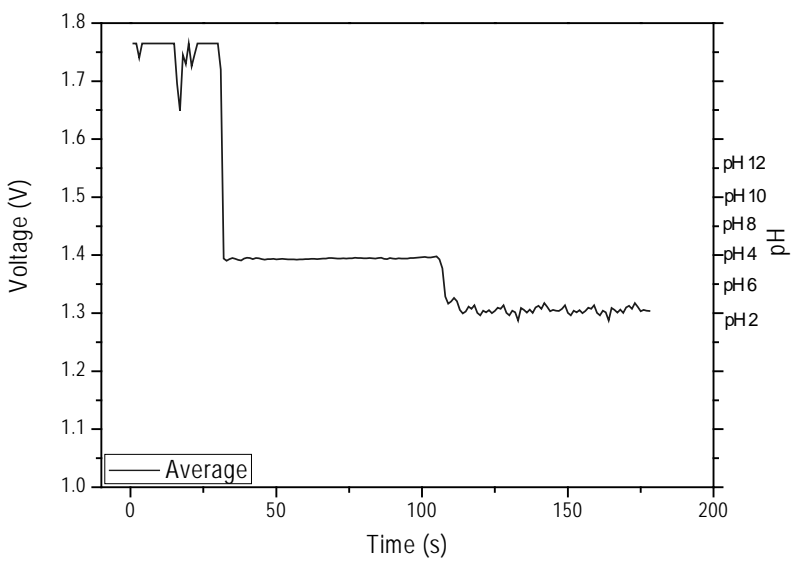

Fig. 11. pHs of gullet and stomach of animal. 


\section{Conclusions}

In this study, we developed a small $\mathrm{pH}$ sensor catheter that could be inserted into an endoscope's working channel of $3 \mathrm{~mm}$ diameter using ISFET and the microreference electrode filled with $\mathrm{KCl}$ gel. The packaging materials were chosen to be suitable for contact with the human body. The sensitivity of the $\mathrm{pH}$ sensor catheter was $43 \mathrm{mV} / \mathrm{pH}$. Its durability was tested at pHs 2 and 7 for $72 \mathrm{~h}$, and the results showed that it worked well. In an animal, it was successfully used to determine $\mathrm{pH}$.

The sensor has potential for commercialization. When the endoscope showed the gullet and stomach, it was found that the catheter can be used to examine those regions as well. The results could be obtained in real time, thus more accurate diagnoses are expected.

\section{Acknowledgements}

This study was supported by the Intelligent Microsystem Center of the 21 st Century Frontier R\&D Projects.

\section{References}

1 R. Pellicano, A. Repici and M. Rizzetto: Minerva Gastroenterol Dietol 50 (2004) 193.

2 B. L. Weusten, L. M. Akkermans, G. P. van Berge-Henegouwen and A. J. Smout: AJPGastrointestinal and Liver Physiology 266 (1994) 357.

3 P. Bergveld: IEEE Trans. Biomed. Eng. 17 (1970) 70.

4 P. Bergveld: Sens. Actuators, B 88 (2003) 1.

5 M. J. Schoning and A. Poghossian: Analyst 127 (2002) 1137.

6 S. Martinoia, N. Rosso, M. Grattarola, L. Lorenzelli, B. Margesin and M. Zen: Biosens. Bioelectron. 16 (2001) 1043.

7 Y. J. Kim, Y. C. Lee, B. K. Sohn, C. S. Kim and J. H. Lee: Electron. Lett. 39 (2003) 1515.

8 G. Mclauchlan, J. M. Rawlings, M. L. Lucas, R. F. Mccoly and G. P. Crean: Gut 28 (1987) 935.

9 S. Ito, H. Hachiya, K. Baba, Y. Asano and H. Wada: Talanta 42 (1995) 1685. 